
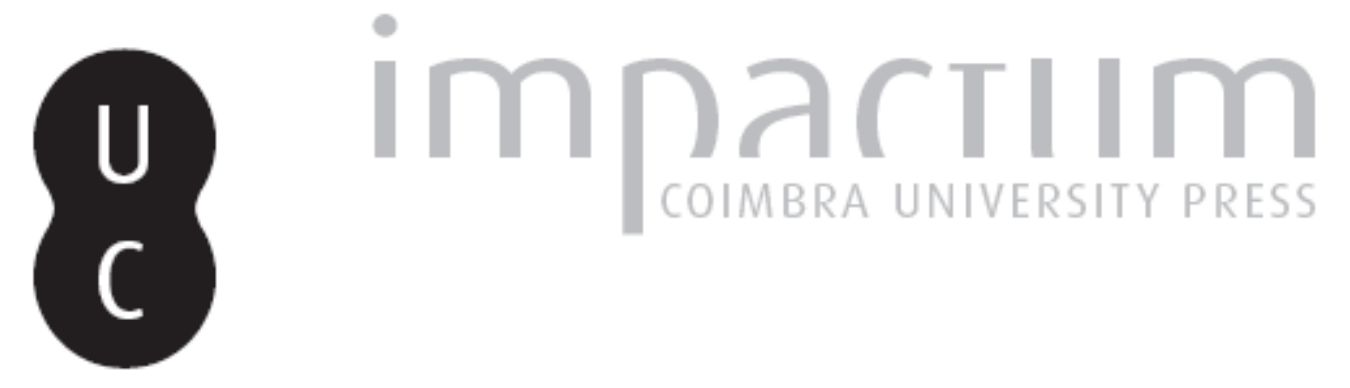

\title{
As romarias no planalto beirão, desde os inícios do século XVIII
}

Autor(es): $\quad$ Silva, José Manuel Azevedo e

Publicado por: Centro de História da Sociedade e da Cultura

URL persistente:

URI:http://hdl.handle.net/10316.2/39396

DOI:

DOI:http://dx.doi.org/10.14195/1645-2259_13_14

Accessed : $\quad$ 26-Apr-2023 14:15:49

A navegação consulta e descarregamento dos títulos inseridos nas Bibliotecas Digitais UC Digitalis, UC Pombalina e UC Impactum, pressupõem a aceitação plena e sem reservas dos Termos e Condições de Uso destas Bibliotecas Digitais, disponíveis em https://digitalis.uc.pt/pt-pt/termos.

Conforme exposto nos referidos Termos e Condições de Uso, o descarregamento de títulos de acesso restrito requer uma licença válida de autorização devendo o utilizador aceder ao(s) documento(s) a partir de um endereço de IP da instituição detentora da supramencionada licença.

Ao utilizador é apenas permitido o descarregamento para uso pessoal, pelo que o emprego do(s) título(s) descarregado(s) para outro fim, designadamente comercial, carece de autorização do respetivo autor ou editor da obra.

Na medida em que todas as obras da UC Digitalis se encontram protegidas pelo Código do Direito de Autor e Direitos Conexos e demais legislação aplicável, toda a cópia, parcial ou total, deste documento, nos casos em que é legalmente admitida, deverá conter ou fazer-se acompanhar por este aviso. 

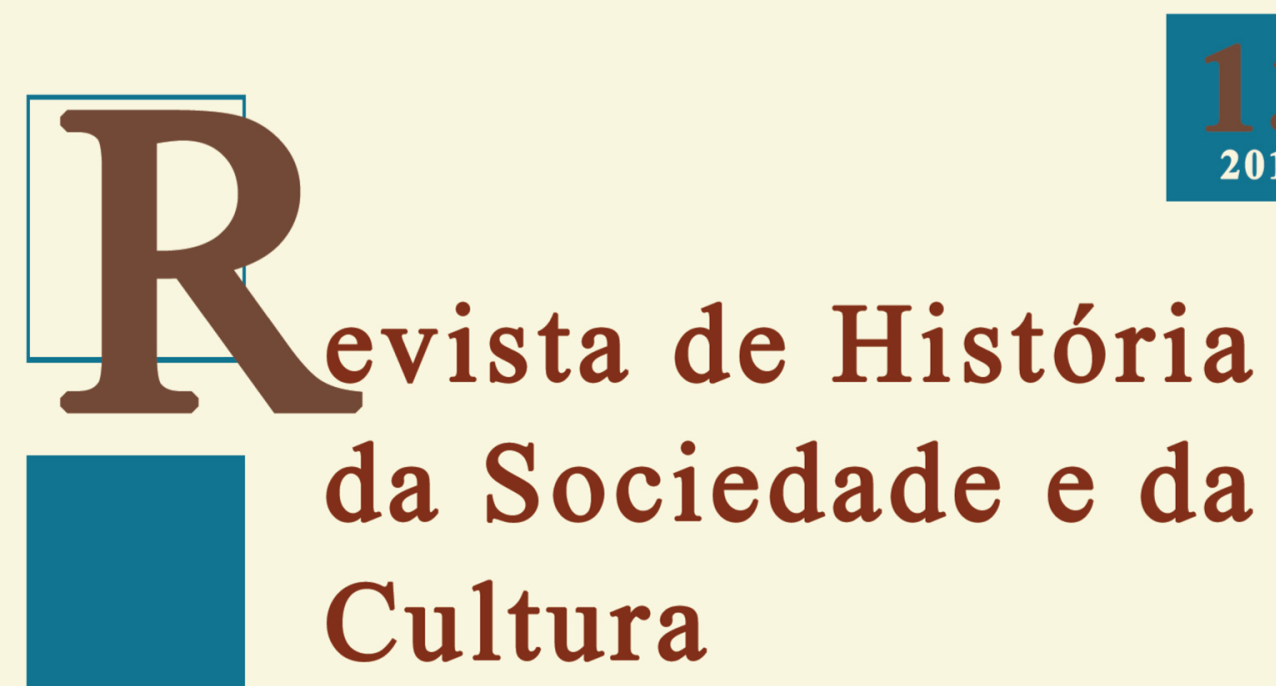

2013

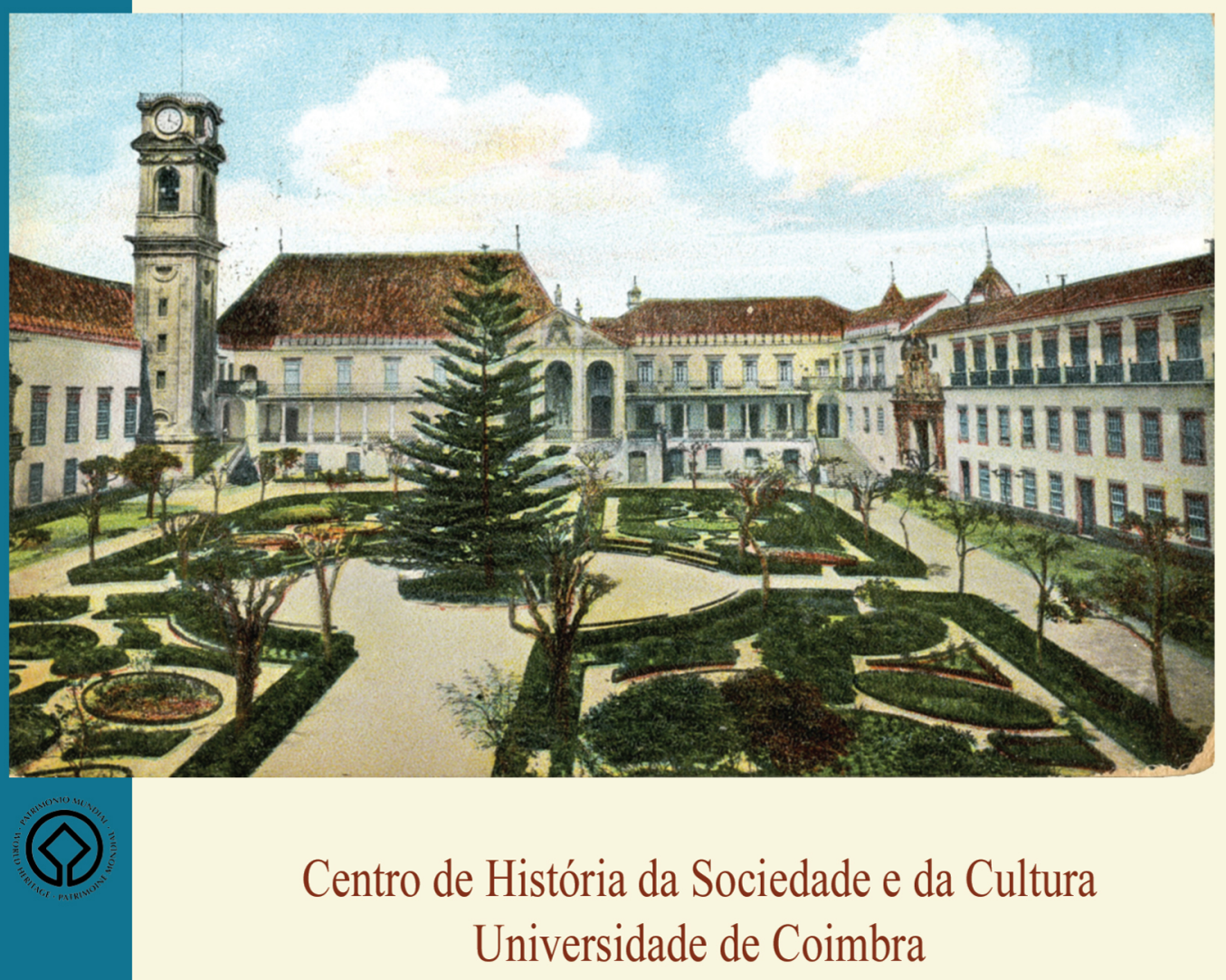

Coimbra 


\title{
As Romarias no Planalto Beirão, desde os inícios do Século XVIII
}

\author{
José Manuel Azevedo e Silva \\ Professor Jubilado da FLUC \\ Membro do Centro de História da Sociedade e da Cultura \\ jazevedosilva@gmail.com \\ Texto recebido em /Text submitted on: 13/03/2013 \\ Texto aprovado em /Text approved on: 15/11/2013
}

\section{Resumo/Abstract:}

Neste estudo, começamos por nos situar nos princípios do século XVIII e por captar a rede de santuários e de outros tipos de templos do planalto beirão dedicados à Virgem Maria, nas suas múltiplas invocações, constantes do Santuário Mariano, de Frei Agostinho de Santa Maria. O autor publicou, em volumes separados, os santuários respeitantes às três dioceses que então (como hoje, com o ajustamento dos seus limites) estão presentes neste espaço geográfico. Seguindo a ordem alfabética, temos as dioceses de Coimbra, da Guarda e de Viseu. Este foi o seu único critério organizativo. Tendo a plena consciência de podermos incorrer nalguma imprecisão, face à divisão administrativa dos concelhos de então e de agora, esforçámo-nos por "arrumar" os templos (santuário, capela, ermida ou igreja matriz) que abrigavam a imagem da Virgem Maria, dentro da jurisdição de cada um dos actuais 17 municípios do planalto beirão. Abordaremos também, ontem como hoje, os cultos não marianos, a simbiose entre o sagrado e o profano e os principais santuários e romarias em honra e glória do Senhor, bem como o sentido das preces ou o cumprimento de promessas dos crentes aos santos e santas da sua devoção.

In this article, we start by placing ourselves at the beginning of the 18th century and mapping, in the so called Planalto Beirão (the Beira Plateau), the network of shrines and other types of temples dedicated to the Virgin Mary, in Her multiple denominations, collected from Santuário Mariano by Agostinho de Santa Maria. This author, in three separate volumes, made an inventory of the shrines located in the three dioceses which, at that time, (as well as today, with some adjustments of their limits), were situated in the mentioned geographical area. Following the alphabetical order, we have the dioceses of Coimbra, Guarda and Viseu. This was the author's only organizational criterion. Being fully aware that we can incur some inaccuracy, given the administrative division of the municipalities of that time and nowadays, we tried to assign to each temple (shrine, chapel, small chapel or parish church) that housed the image of the Virgin Mary, a place within the jurisdiction of each of the existing 17 municipalities of the Beira Plateau. We also approached - in the past and nowadays non-Marian worship, the symbiosis between the sacred and the profane and the main shrines and pilgrimages in honour and glory of the Lord, as well as the meaning of prayers and the fulfilment of promises that believers made to the saints of their devotion.

Palavras chave/Keywords:

Romarias; Planalto beirão; Templos; Culto mariano; Outros cultos.

Popular pilgrimages; Beira Plateau; Temples; Marian worship; Other forms of worship. 
As romarias de antanho eram (e continuam a ser) um bom exemplo da simbiose entre o sagrado e o profano e pressupunham uma dupla caminhada dos romeiros entre a sua morada e a capela, ermida, igreja ou santuário que albergava a sagrada imagem da sua veneração. No aspecto religioso, assumiam dois sentidos: o da prece, na perspectiva de obter do santo ou santa da sua devoção determinada "maravilha" (milagre) pela sua intercessão junto de Deus; o do cumprimento da promessa anteriormente feita e já milagrosamente satisfeita. Retenha-se que, milagres, só Deus os faz. Os santos são meros intercessores e instrumentos dessas teofanias. Na esfera do profano, o caminho de ida e de regresso (principalmente o primeiro) e os momentos passados no exterior do templo, mais intensos se havia arraial e/ou feira, eram tempo de manifestações de alegria e de festa.

Objectar-se-á que hoje continuam a realizar-se romarias. É verdade, mas a grande maioria dos romeiros desloca-se de automóvel ou de autocarro e, em relação àqueles que vão a pé, porque essa caminhada faz parte da prece ou do cumprimento do voto, não se vê, como outrora, ninguém a cantar e a dançar ao som de flautas, de pífaros, de instrumentos de cordas, de concertinas, de harmónicas bucais, de pandeiros, de pandeiretas, de ferrinhos.

Vejamos os 108 templos marianos do planalto beirão, seguindo a ordem alfabética das dioceses e dos concelhos.

\section{Na diocese de Coimbra}

Arganil: Nossa Senhora de Montalto, no alto da vila; Nossa Senhora do Loureiro, junto à povoação de Pombeiro.

Celorico da Beira: Nossa Senhora da Anunciada, entre as vilas de Linhares e da Mesquitela "em terras de huma quinta dos senhores de Mello" (ermida particular); Nossa Senhora da Saúde, no lugar de "Villa Sueyro do Chão"; Nossa Senhora da Ajuda, na "Villa da Mesquitella”; Nossa Senhora da Graça era patrona do lugar de Vila Ruiva, mas a sua imagem estava na matriz da Mesquitela.

Gouveia: Nossa Senhora da Vera Cruz, em "hum outeiro"; Nossa Senhora de Celas, nas margens do Rio Torto "quando se vay meter no Mondego"; Nossa Senhora do Monte, em Mangualde da Serra; Nossa 
Senhora do Couto, junto à estrada "que vay de Gouvea para Mello"; Nossa Senhora da Sedarça, no "termo de Folgosinho"; Nossa Senhora dos Linhares (actual Senhora dos Verdes'), situada "em hum monte, a que chamão o monte Algião"; Nossa Senhora das Neves, "em huma Capela" do convento das "Religiosas de Santa Clara”, de Vinhó; Nossa Senhora do Porto, "fora da Villa de Gouvea, e junto ao rio Mil"; Nossa Senhora da Estrela, do lugar de São Paio; Nossa Senhora da Tosse, cuja imagem estava na mesma ermida de Nossa Senhora da Estrela.

Oliveira do Hospital: Nossa Senhora das Preces ou do Culcurinho, no "termo da vila de Avô", freguesia da Aldeia das Dez; Nossa Senhora do Mosteyro, ou das Neves, "junto da Villa de Avô".

Santa Comba Dão: Nossa Senhora do Rosário, imagem colocada no altar colateral da parte do evangelho da igreja matriz da povoação de Couto do Mosteiro; Nossa Senhora da Assunção, padroeira de Treixedo, com a sua imagem colocada no centro do altar-mor.

Seia: Nossa Senhora da Ribeira, na freguesia de Folhadosa, "em alegre campo vizinho à ribeyra, ou rio Alva”; Nossa Senhora do Espinheiro, no lugar de Póvoa Velha, da "Parochia da Villa de Cea, que lhe fica em distância de meya legoa”; Nossa Senhora da Lomba, "a norte do lugar de Pinhanços"; Nossa Senhora do Desterro, de S. Romão, "distante da Villa meya legoa e do rio Alva cousa de trinta passos"”.

\section{Na diocese da Guarda}

Relembrando o que em outro lugar foi dito, convém esclarecer que, do concelho da Guarda, apenas nos interessa a parte voltada para oeste.

1 CRESPO, José - Romarias Típicas da Beira. A Senhora dos Verdes. Beira Alta. XLIII, no 4 (1984) 597-600.

2 SANTA MARIA, Frei Agostinho de - Santuário Mariano.... Lisboa: Na Officina de António Pedroso, Galram, 1707-1723, vol. IV, p. 494-678. O santuário de Nossa Senhora do Desterro, com suas dez capelinhas, fica a $3 \mathrm{~km}$ de S. Romão, junto ao rio Alva. A sua festividade é a 2 de Abril. Até à primeira metade do século XX era uma grande romaria, aí acorriam os pastores com seus rebanhos, sendo representado um votivo auto pastoril. Cf. BRAGA, Teófilo - História da Poesia Popular Portuguesa, $3^{\text {a }}$ edição, 2 vols., Lisboa: Manuel Gomes-Editor, 1902-1905, p. 258-260. 
Acontece ainda que, no tempo em que Frei Agostinho de Santa Maria escreveu o Santuário Mariano, os então municípios de Linhares e de Mesquitela, hoje integrados no concelho de Celorico da Beira, pertenciam à diocese de Coimbra e só o restante território deste município era da jurisdição da diocese da Guarda. Daí que nos volte a aparecer aqui de novo Celorico da Beira. Idêntica situação ocorria no território do actual concelho de Santa Comba Dão, então partido entre as dioceses de Coimbra e de Viseu.

Celorico da Beira: Nossa Senhora dos Açores, na aldeia de Açores, a uma légua e meia de distância a les-nordeste da vila de Celorico. A imagem desta Senhora está ligada à lenda do açor ${ }^{3}$.

Guarda: Nossa Senhora do Templo, com santuário situado "fora dos muros da Cidade da Guarda, para a parte do Occidente".

\section{Na diocese de Viseu}

Aguiar da Beira: Nossa Senhora da Purificação, em Pena Verde, perto de Queiriz e de Dornelas; Nossa Senhora do Castelo, em um monte próximo da vila; Nossa Senhora da Luz, na aldeia de Coruche, termo desta vila; Nossa Senhora da Conceição, "do mesmo Lugar de Coruche”, em um vizinho monte fora da aldeia; Nossa Senhora do Carregal, "do Lugar da Cortiçada", no monte da Cavaca; Nossa Senhora do Pilar "da mesma Parochia da Cortiçada" (capela particular); Nossa Senhora do Pranto, próximo da aldeia do Souto; Nossa Senhora das Neves, padroeira da igreja matriz de Gradiz, colocada no altar-mor; Nossa Senhora do Vencimento ou do Mosteiro, a meia légua da aldeia e freguesia do Pinheiro ${ }^{4}$. Embora Nossa Senhora da Lapa fique já nos limites de Sernancelhe, muitos romeiros do concelho de Aguiar da Beira e de outros do planalto beirão acorriam em romaria ao seu santuários.

3 SANTA MARIA, Frei Agostinho de - ob. cit., vol. III, p. 32-57.

4 Cf. COSTA, Fernando Jorge dos Santos - Aguiar da Beira - Monografia. Aguiar da Beira: Município de Aguiar da Beira, 2009, p. 200-202.

5 Ibidem, p. 35 e 36; VASCONCELLOS, J. Leite de - Romanceiro Português. Coimbra: Universidade de Coimbra, 1960, vol. II, p. 505. 
Carregal do Sal: Nossa Senhora dos Milagres, na Lomba de Santiago, "junto ao Lugar de Lanceyras", paróquia de Cabanas; Nossa Senhora dos Carvalhais, "junto a huma Ribeyra, a que dão o nome de Cabaninhas, e em pouca distância do Lugar de Alvarellos "; Nossa Senhora das Boas Novas, na aldeia do Sobral, freguesia de Papízios; Nossa Senhora da Arnoza, na Póvoa de Arnoza, freguesia de Papízios (ermida particular); Nossa Senhora da Conceição, na aldeia de Pinheiro, freguesia de S. Miguel de Papízios.

Mangualde: Nossa Senhora do Castelo, no alto do monte fronteiro à sede do concelho; Nossa Senhora de Cervães, próximo desta localidade; Nossa Senhora dos Remédios, igualmente na Póvoa de Cervães; Nossa Senhora dos Verdes, em Abrunhosa-a-Velha; Nossa Senhora do Bom Sucesso, no alto do monte da então vila de Chãs de Tavares; Nossa Senhora do Pranto, no alto de um monte junto à povoação de Guimarães de Tavares; Nossa Senhora da Saúde, na Cunha Alta, à beira da "estrada Real, que faz caminho para o Concelho de Tavares, e para a Praça de Almeida e para outras muytas terras"; Nossa Senhora da Assunção, também na aldeia e paróquia da Cunha Alta; Nossa Senhora dos Prazeres, a alguma distância a sudoeste de Aldeia de Carvalho, freguesia de Alcafache; Nossa Senhora das Neves, próximo da aldeia e paróquia de Lobelhe do Mato; Nossa Senhora do Monte ou Nossa Senhora da Cabeça, num ponto alto da cerca do Mosteiro de Maceira Dão ${ }^{6}$.

Nelas: Nossa Senhora do Viso, no alto de um monte de Carvalhal Redondo; Nossa Senhora da Tosse, na aldeia de "Toladal” (actual Folhadal), freguesia de Nelas; Nossa Senhora do Viso, em Canas de Senhorim; Nossa Senhora da Expectação, em Vilar Seco (a sua antiga ermida passou a ser a igreja matriz quando foi criada a paróquia).

Penalva do Castelo: Nossa Senhora da Consolação, no Casal das Donas, aldeia da freguesia de S. Pedro do Castelo de Penalva; Nossa Senhora da Ribeira, de Entre as Águas, entre o rio Dão e o seu afluente Coja; Nossa Senhora da Expectação ou da Corga, na aldeia da Corga, freguesia de S. Martinho de Pindo; Nossa Senhora da Assunção, "da mesma freguesia

6 Para uma abordagem explicativa dos onze santuários marianos do actual termo do concelho de Mangualde, veja-se SILVA, José Manuel Azevedo e - Notícias e Memórias Paroquiais Setecentistas - Mangualde. Coimbra: Palimage - Centro de História da Sociedade e da Cultura, 2009, p. 102-111. 


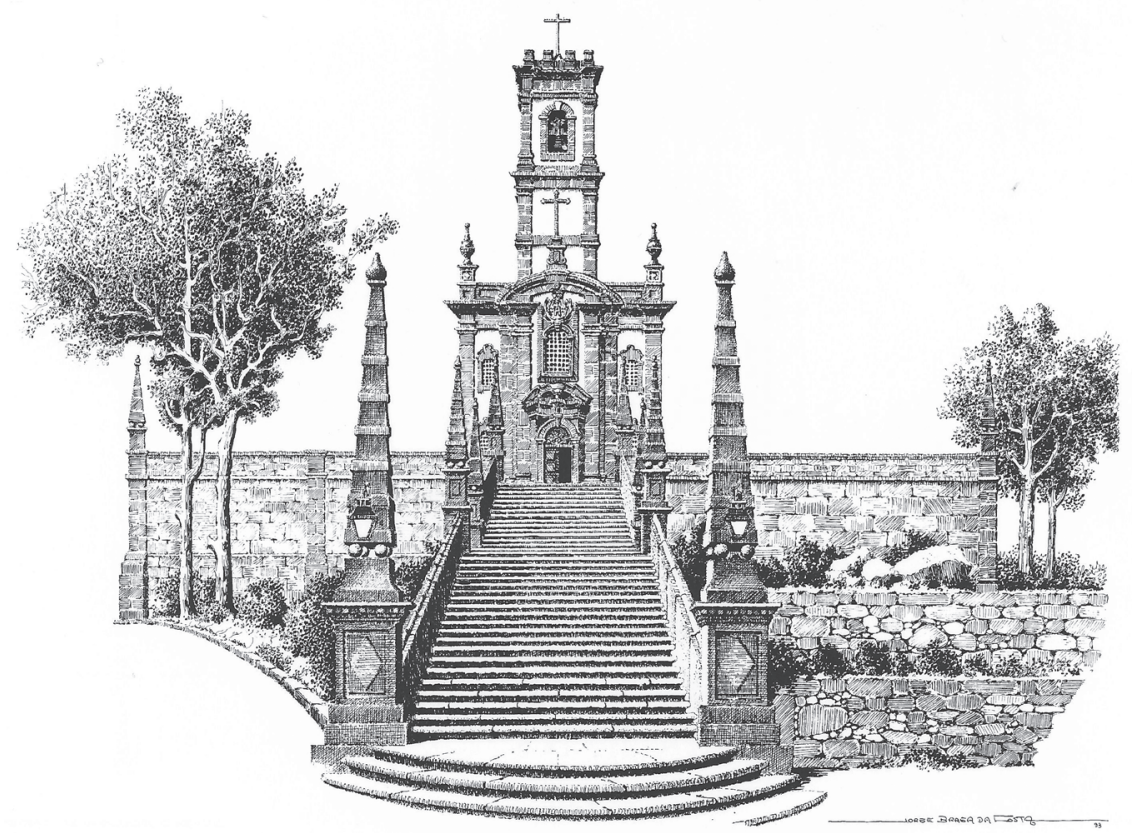

Santuário de Nossa Senhora do Castelo - Mangualde

de S. Martinho"; Nossa Senhora da Ribeira, na freguesia da Ínsua, entre o rio Dão e a ribeira de Coja, junto a esta (alguns dão-lhe o título de Senhora da Luz).

Santa Comba Dão: Nossa Senhora da Ribeira ou do Pranto, junto ao rio Mondego, na paróquia de Pinheiro de Ázere.

Sátão: Nossa Senhora das Romãs, no côncavo do promontório do Barrocal, próximo da aldeia de Romãs, "do termo de Gulfar”, quatro léguas a leste de Viseu; Nossa Senhora da Esperança, na aldeia de Abrunhosa, freguesia de S. Miguel de Vila Boa.

Tondela: Nossa Senhora da Natividade, de Besteiros, também venerada sob a invocação de Nossa Senhora do Campo; Nossa Senhora da Esperança, no lugar e freguesia de S. Pedro de Mouraz, "dista da Cidade de Viseu três legoas e meya para a parte do sul, e meya legoa da Villa de Tondella, e ficará distante da estrada Real, que vay para Coimbra, pouco mais de dous tiros de mosquete"; Nossa Senhora de Guadalupe, da paróquia de “Ardavaz”, actualmente Dardavaz; Nossa Senhora do Castro, na freguesia 
de S. Julião da Lomba, "termo de Besteyros"; Nossa Senhora da Expectação ou da Rua Fria, a leste da aldeia de Santa Ovaia de Baixo, freguesia de Canas de Sabugosa; Nossa Senhora do Rosário, "do Lugar e Freguesia de Villar”, do termo de Besteiros; Nossa Senhora da Penha de França, em um monte próximo da aldeia de Muna, freguesia de Santiago, termo de Besteiros; Nossa Senhora da Assunção, padroeira da igreja matriz de Tondela, com a imagem colocada no altar-mor; Nossa Senhora do Guardão, junto ao lugar e freguesia de Guardão; Nossa Senhora do Rosário, venerada na igreja matriz de Guardão, no altar colateral do lado da epístola; Nossa Senhora da Assunção, a que vulgarmente chamam Senhora da Ribeira, na freguesia de Parada; Nossa Senhora do Pranto, em Sabugosa; Nossa Senhora da Conceição, na aldeia de Parada, freguesia de S. Miguel do Outeiro; Nossa Senhora das Neves, no altar lateral do lado da epístola da igreja matriz de Ferreirós, junto ao rio Dão.

Viseu: Nossa Senhora de Pedrogal, padroeira da sé de Viseu, com a sua imagem colocada no altar-mor (os da cidade chamavam-lhe "Nossa Senhora do Altar-Mor" e outros Nossa Senhora da Assunção); Nossa Senhora de Silgueiros ou da Assunção, na paróquia de Silgueiros; Nossa Senhora da Conceição, com imagem colocada na capela do lado do evangelho da igreja do Convento de S. Francisco de Orgens; Nossa Senhora da Luz, lugar e paróquia de Farminhão; Nossa Senhora da Anunciação, no lugar de Carracedo, paróquia de Farminhão, "em distância de hum quarto de legoa", a norte; Nossa Senhora da Conceição, numa ermida anexa à igreja matriz de Farminhão; Nossa Senhora do Rosário, na igreja matriz de Farminhão; Nossa Senhora do Carmo, venerada também na igreja matriz de Farminhão; Nossa Senhora das Neves, numa pequena ermida da Quinta do Outeiro, paróquia de S. Miguel, "termo da cidade”; Nossa Senhora da Vitória, do lugar de Carragozela, paróquia de Cavernães, cerca de uma légua a nascente da cidade; Nossa Senhora do Castro, em um monte alto, no lugar de Vila de Souto, uma légua a norte da cidade; Nossa Senhora do Ribeiro, junto de um pequeno ribeiro, perto do lugar de Routal, paróquia de Torredeita; Nossa Senhora da Expectação ou do Ó, na freguesia de São Cipriano, no alto do monte da Portela, uma légua a ocidente de Viseu; Nossa Senhora das Neves, na aldeia e freguesia do Salvador, próximo da cidade de Viseu, a sul, junto ao rio Pavia; Nossa Senhora da Conceição, no Campo da Cava 
de Viriato; Senhora da Oliveira ou do Ó, na aldeia de Oliveira, freguesia de S. João de Lourosa e a sua ermida também era chamada da Senhora do Ó ou da Expectação do Parto; Nossa Senhora dos Prazeres, na povoação de Abraveses, anexa à freguesia da Sé; Nossa Senhora dos Prazeres, no lugar de Pascoal, próximo de Abraveses; Nossa Senhora do Freixo, junto à aldeia de Sanguinhedo (onde terá existido um antigo freixo), da freguesia de Côta; Nossa Senhora da Conceição, no lugar e paróquia de Mondão, uma légua a norte de Viseu; Nossa Senhora da Conceição, dentro de Mondão, fundada por António Rebelo Velho e benzida em 9 de Setembro de 1685 (capela particular); Nossa Senhora da Expectação ou da Prenhada, na Quinta do Covelo, de Valeriano Coelho de Sousa, a oriente da cidade, na freguesia de S. Pedro de França (capela particular); Nossa Senhora da Penha ou da Pena, no alto de um monte, defronte da Quinta do Covelo, freguesia de S. Pedro de França; Nossa Senhora do Ribeiro de Frades, na Quinta dos Frades, de António Coelho de Campos, freguesia de S. João de Lourosa (capela particular); Nossa Senhora da Nazaré, em Lourosa de Baixo; Nossa Senhora dos Escravos, em Lourosa de Cima; Nossa Senhora da Estrela, na aldeia do Souto, freguesia de S. João Baptista, a ocidente de Viseu; Nossa Senhora do Egipto, na freguesia de S. Cipriano, uma légua a ocidente da cidade; Nossa Senhora da Victória, na aldeia de Mozelos, freguesia do Campo da Madalena, meia légua a Norte de Viseu; Nossa Senhora da Ouvida, do Rosário ou das Neves, a Leste da povoação de Ranhados, da freguesia da sé; Nossa Senhora do Rosário, em Santos Evos, uma légua a leste da cidade; Nossa Senhora do Rosário, na capela colateral do lado da epístola da igreja matriz da paróquia de Campo, próximo e a norte da cidade 7 .

\section{4. $O$ culto mariano}

Tomando o que atrás ficou dito, seguindo o autor do Santuário Mariano, existiam, nos princípios do século XVIII, no território do planalto beirão, 108 templos com imagens de diversas invocações de Nossa Senhora (21 na diocese de Coimbra, 2 na da Guarda voltada para o planalto, e 85

\footnotetext{
${ }^{7}$ SANTA MARIA, Frei Agostinho de - ob. cit., vol. V, p. 141-537 e vol. VII, p. 465-467.
} 
na de Viseu). Desta totalidade, 8 tinham a respectiva imagem em capelas particulares, 6 em mosteiros e 11 no altar-mor ou num dos altares colaterais de uma igreja matriz. Feitas as contas, temos que 85 invocações marianas tinham templo próprio (santuário, igreja, capela, ermida).

Convém sublinhar que 40 (37\%) dos templos marianos tinham irmandades, com um corpo de irmãos geralmente numeroso e de composição bastante diversificada. Vejamos alguns exemplos mais representativos: a de Nossa Senhora de Silgueiros, ou da Assunção, congregava "cem Irmãos Leygos”; a de Nossa Senhora do Ribeiro, de Torredeita, tinha 171 irmãos leigos e 9 sacerdotes; a de Nossa Senhora da Expectação, de Santa Ovaia de Baixo, era formada por 70 irmãos, 30 irmãs, 1 capelão a alguns sacerdotes; a de Nossa Senhora da Penha de França contava 200 irmãos e 50 irmãs; a de Nossa Senhora da Assunção, de Tondela, dispunha de muitos leigos e 70 sacerdotes; a de Nossa Senhora do Rosário, da matriz de Guardão, incorporava 150 irmãos casados e suas mulheres; a de Nossa Senhora da Purificação, de Pena Verde, tinha 120 irmãos, 30 irmãs e 12 sacerdotes; a de Nossa Senhora das Neves, de Gradiz, era constituída por 250 irmãos; a de Nossa Senhora da Ouvida, do Rosário ou das Neves, de Ranhados, tinha 160 irmãos e 25 irmãs donzelas e viúvas; a de Nossa Senhora da Victória, de Mozelos, contava apenas 33 irmãos; a de Nossa Senhora dos Verdes, de Abrunhosa-a-Velha, tinha 200 irmãos; a de Nossa Senhora dos Prazeres, de Aldeia de Carvalho, constava 150 irmãos e 10 irmãs; a de Nossa Senhora das Neves, de Lobelhe do Mato, congregava 150 irmãos e 12 irmãs, provenientes de 5 freguesias (Lobelhe, Fornos de Maceira Dão, Alcafache, Moimenta do Dão e Espinho) ${ }^{8}$. Caso curioso é o de Nossa Senhora do Rosário, do lugar e freguesia de Vilar (Besteiros) que tinha 2 irmandades ${ }^{9}$. Em alguns casos, não é indicado o número de irmãos, mas o autor do Santuário Mariano regista expressões como "tem hũa nobre Irmandade".

Muitas das imagens de Nossa Senhora tinham, naquela época, tomado o nome da povoação, do sítio ou das suas características geográficas ou mesmo de um elemento da flora. Ilustremos com alguns exemplos: Senhora

${ }^{8}$ Ibidem, vol. V, p. 192-197, 245-251, 291-297, 304, 309, 372-374, 386-389, 427 e 428 , 443 e 444, 528-532, 524, 526, 183-185, 500-505, 496-500. No presente, os irmãos e irmãs são apenas de Lobelhe e de Moimenta.

9 Ibidem, p. 300-304. 
do Monte, Mangualde da Serra (Gouveia), porque a imagem aparecera no "Monte Alfatema, entre tres carvalhos"; Senhora da Ribeira, em Folhadosa (Seia), porque o santuário ficava "vizinho à ribeyra ou rio Alva"; Senhora do Espinheiro, da Póvoa (Seia), onde terá existido um velho espinheiro; Senhora dos Linhares, Aljão (Gouveia), onde eram cultivados mimosos campos de linho; Senhora dos Carvalhais (Carregal do Sal); Senhora do Ribeiro, porque o santuário estava junto de um pequeno ribeiro, perto da povoação de Routal (Viseu); Senhora da Ribeira ou de Entre as Águas (Penalva do Castelo), porque a sua "Casa" ficava entre o rio Dão e a foz do seu afluente Coja); Senhora do Freixo, Sanguinhedo (Viseu), pois, segundo tradição antiga, aqui terá existido um velho freixo); Senhora dos Escravos, Lourosa de Cima (Viseu), pelo facto de os devotos que fundaram a sua primitiva ermida se terem considerado seus escravos; finalmente, em relação à Senhora do Loureiro, "junto à Villa de Pombeyro" (Arganil), é caso para questionar por que não tomou o nome de Pombeiro e sim o de Loureiro ${ }^{10}$.

Quanto ao culto dos devotos perante os "prodígios e maravilhas" que as diferentes invocações de Nossa Senhora obravam, podemos dizer que muitas intercediam perante Deus no domínio da "clínica geral", outras eram portadoras de certas "especialidades", outras ainda não deixavam de atender aos aspectos gerais, mas eram mais "eficazes" num determinado domínio específico. Por outro lado, as invocações de alguns santuários marianos eram objecto de uma devoção local, muitas abrangiam romeiros devotos de povos circunvizinhos e algumas atraíam peregrinos de lugares longínquos e, nestes casos, os santuários tinham, normalmente, casas próprias para acolher os romeiros, durante uma ou mais noites.

Vamos documentar: Nossa Senhora do Monte, de Mangualde da Serra (estando na Serra da Estrela, advogava a favor dos mareantes) "todos os que a invocavão, assim na terra como no mar, achavão prompta a sua protecção, porque os enfermos em terra achavão certo o remédio de sua saúde, e os que no mar se vião naufragar, erão livres do perigo logo que invocavão esta Soberana Estrella, e chegavão ao porto com bonança”; à Nossa Senhora da Tosse, de S. Paio (Gouveia), deram-lhe esta invocação

${ }^{10}$ Ibidem, vol. IV, p. 511-513, 527-529, 529-531, 531 e 532; vol. V, p. 210-214, 245-251, 461-467, 486-488; vol. VII, p. 465-467. 
"por ser advogada desta moléstia, e enfadonha queyxa"; em relação a Nossa Senhora de Pedrogal, da Sé de Viseu "a devoção, que toda aquela Cidade tem a esta Senhora he muyto grande; he não só os moradores della, e os de todo aquelle Bispado, mas ainda de fora delle vem muytas pessoas com grande devoção a buscar nesta milagrosa Senhora o alivio em seus trabalhos, e o remédio de suas necessidades"; o santuário de Nossa Senhora do Espinheiro, da Póvoa Velha (Seia) tem "muytas casas de romagem, aonde pousão, e descansão os romeyros, e peregrinos". Nossa Senhora de Treixedo (Santa Comba Dão) obrava "muytas maravilhas, e milagres a favor dos seus devotos, e principalmente nas mulheres, que padecem faltas de leyte para alimento de seus charos filhinhos"; a Nossa Senhora da Pena ou da Penha (Viseu) "tem muyta fé, e devoção os moradores do Lugar do Covello"; à festividade de Nossa Senhora do Monte ou da Cabeça, no Mosteiro de Maceira Dão (Mangualde), no dia 3 de Maio (mais tarde passará para Quinta-Feira de Ascensão) acorria muita gente das redondezas "em romaria a visitar aquella milagrosa Imagem", com suas ofertas em acção de graças pela cura dos seus achaques, particularmente as "dores de cabeça" ${ }^{11}$.

\section{Evolução dos santuários e das romarias}

A realidade do universo dos santuários e das romarias não é estática. O culto e a devoção de algumas das invocações podiam aumentar ou, ao invés, entrar em decadência e, normalmente, os seus templos em ruínas. Em relação a Nossa Senhora do Mosteiro ou das Neves, de Avô, diz Frei Agostinho de Santa Maria, em 1712, que “antigamente era Santuário muyto celebre, e venerado, erão grandes os concursos das romagens, mas como a frieza humana he tão grande, faltando quem accenda, e excite o fogo da devoção, não so esta se esfria, mas se acaba de todo"' ${ }^{2}$. Situação idêntica acontecia, em 1716, com Nossa Senhora de Silgueiros ou da Assunção ${ }^{13}$.

${ }^{11}$ Ibidem, vol. IV, p. 511-513, 529-531, 674; vol. V, p. 141-144, 214-218, 496 e 497, 514-516.

${ }^{12}$ Ibidem, vol. IV, p. 648-651

${ }^{13}$ Ibidem, vol. V, p. 197. 
Por outro lado, alguns santuários marianos e respectivas romarias foram sendo restaurados e ampliados e outros foram surgindo até aos nossos dias.

\section{Romarias e santuários não marianos}

Embora em menor número, não podemos esquecer santuários e romagens de padroeiros não marianos. Destaquemos, entre outros, os casos das grandes romarias do planalto beirão em honra do Senhor do Calvário, em Gouveia, ou do Senhor dos Caminhos, no Sátão. E outros exemplos podem aduzir-se, nomeadamente, as festas e romarias em honra do Senhor do Calvário na Lajeosa do Dão (Tondela) e na Folhadosa (Seia); do Anjo da Guarda, em Vila Chã (Seia); de Santa Eufémia, em Celorico da Beira (romaria e feira), na Matança, Fornos de Algodres (romaria e feira); em Tondela, em Nelas, em Cepões (Viseu) e em Paranhos (Seia); de S. Bartolomeu, em Senhorim, concelho de Nelas (festa, romaria e banho purificador no Rio Santo) ${ }^{14}$; de São Miguel, na Muxagata (Fornos de Algodres); de S. Brás, em Juncais e de Santo Amaro, na Fuinha, Fornos de Algodres (romarias e feiras) ${ }^{15}$; do Senhor dos Milagres (Tábua), do Senhor da Serra, Carapinha (Tábua). Do Senhor do Castelinho, no lugar de Ancinho (Aguiar da Beira), a que está ligada a lenda de uma mulher que terá sonhado com a imagem de Nosso Senhor perdida nuns penhascos e que tem a sua festa na "primeira dominga de Setembro com grande romaria"16.

${ }^{14} \mathrm{Na}$ tarde de 23 de Agosto, «ao aproximar-se do Poço Santo, a procissão, e preparando-se o pároco para o benzer, já muitos doentes se aglomeram nas duas margens: e mal o sacerdote deita a bênção, logo aqueles começam tomando banho, isto é, banho santo, no açude, e qual mais prestes». Ver LOUREIRO, J. Pinto - O Concelho de Nelas, antiga Terra de Senhorim. Coimbra: Instituto de Coimbra, 1940, p. 207.

${ }^{15}$ Relativamente às festas e romarias do concelho de Fornos de Algodres, veja-se MARQUES, Monsenhor José Pinheiro - Terras de Algodres (Concelho de Fornos), Reedição facsimilada conforme a primeira edição, de 1938. Fornos de Algodres: Câmara Municipal de Fornos de Algodres, 2001, p. 188 e 189.

${ }^{16}$ COSTA, Fernando Jorge dos Santos - ob. cit., p. 238, 239 e 425-427. 


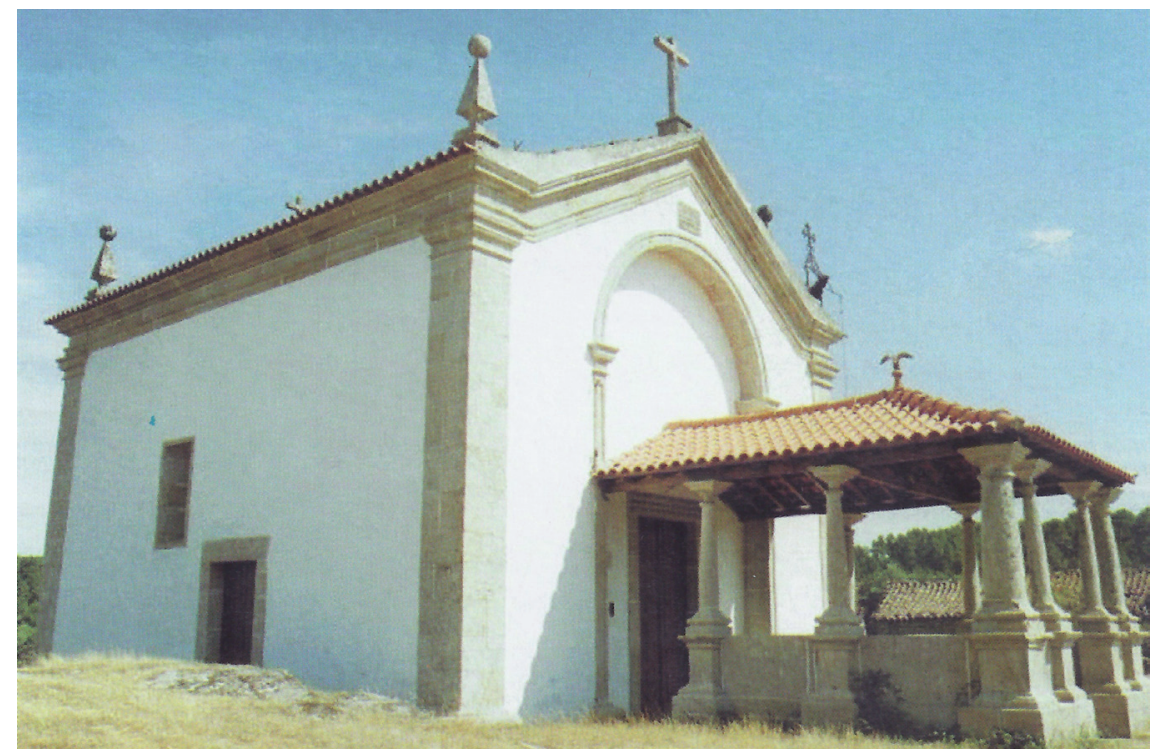

Ermida do Senhor do Castelinho, em Ancinho (Aguiar da Beira)

\section{O sagrado e o profano nas romarias}

Como expressivamente diz Lucena do Vale, referindo-se às afamadas romarias da Senhora do Castelo, de Mangualde, do Senhor dos Caminhos, de Sátão, da Santa Eufémia, de Ranhados, da Senhora dos Verdes, de Fornos de Algodres, da Senhora do Viso, de S. Bartolomeu, «havia-as que desbancavam povo de três e mais léguas em redor. Vinham os romeiros, em grandes ranchos, alegres, endomingados, de pé descalço por mor da caminhada, eles de camisa branca, alva de neve, de casaco ao ombro, as botas enfiadas no varapau pelas presilhas; elas, garridas, de blusas berrantes, saia preta, os sapatos na mão, "xales" de merino à cabeça, sobre os cestos da merenda. E a caminhada sob o sol primaveril ou à torreira do verão, regada com vinho do barril ou da borracha a tiracolo, amenizada com a música da cantiga, era já uma reinação» ${ }^{17}$ :

${ }^{17}$ Como vemos, as manifestações profanas das romarias não aconteciam apenas junto aos santuários, ocorriam também e principalmente durante o percurso a pé do caminho de ida (com mais exuberância) e no de regresso. Por outro lado, convém relevar que a realidade 
Cá vamos p'rá romaria,

A cantar e a dançar!

Tristezas não pagam dívidas,

Rapazes toca a $\operatorname{gozar}^{18 !}$

Por vezes, iam de véspera para não perderem a missa nem o sermão do dia e, «toda a tarde, após o almoço suculento, por entre as mesas do doce os beijos, as cavaquinhas, corações, pirolitos e laranjadas - era um regabofe de se lhe tirar o chapéu! A banda de música, no coreto coberto com ramos de loureiro, enchia os ares de sons estridentes e alegres que desanuviavam os espíritos; os foguetes arrebentavam nos ares e o povo dançava e ria! As pipas de vinho, sobre os carros de bois, despejavam-se umas atrás das outras» ${ }^{19}$.

Também, com muita frequência, as romarias foram e continuam a ser ocasiões de feira. E, nestes casos, o profano precede o sagrado, uma vez que, por regra, as feiras e as festas profanas, nomeadamente as romarias a pé no percurso de ida, precedem as religiosas. Já nos princípios do século XVIII, havia feira na festividade de Nossa Senhora da Natividade, de Besteiros (Tondela) na de Nossa Senhora de Guadalupe, em Ardavaz (Tondela), na de Nossa Senhora da Expectação ou da Corga (Penalva do Castelo), na de Nossa Senhora de Cervães (Mangualde), onde se faziam "outros muytos festejos, de danças, e comédias ”, na de Nossa Senhora da Conceição, do Campo de Viriato (Viseu), celebrada em 8 de Setembro, onde desde há muito se fazia "huma notável feyra que veio a dar origem à Feira de São Mateus, em 21 desse mês" 20.

Mas, mesmo quando tal não sucedia formalmente, nas imediações do santuário, na sequência do que atrás se disse, além dos coretos para os concertos das bandas filarmónicas, «alinhavam-se sempre tendinhas de doce, de "comes e bebes", melancias aos montes, tascos improvisados debaixo

traçada por A. Lucena do Vale para esta região pode estender-se, com uma ou outra variante, a todo o planalto beirão.

${ }^{18}$ VALE, A. Lucena - De passeio à Beira Alta, $2^{\mathrm{a}}$ edição (1 $1^{\mathrm{a}}$ edição em 1956). Lisboa: Direcção Geral da Educação Permanente, 1973, p. 51 e 52.

${ }^{19}$ Ibidem, p. 52.

${ }^{20}$ SANTA MARIA, Frei Agostinho de - ob. cit., vol. V, p. 145-153, 228-230, 468-471, 163-166 e 318-324. 
de qualquer árvore, com o pipo amarrado ao carro, flores de papel, louça, cestos, por vezes especialidades ou artesanato local, bugigangas, etc $»^{21}$.

Um caso muito peculiar é a tradicional romaria da Tia Baptista. Soror Baptista do Céu Custódia ingressou no convento franciscano de Vinhó (Gouveia) e tomou hábito em 1701, aos 22 anos. Segundo a tradição e a penumbra da lenda, sempre manifestou extremoso enlevo pelo Menino Jesus. O povo foi-lhe atribuindo sucessivos milagres, "canonizou-a" com o nome carinhoso de Tia Baptista e prestou-lhe acrisolado culto, emergente da mais genuína crença popular. A esta festa sempre afluíram, desde o século XVIII, muitos romeiros de várias léguas em redor. Dantes, «o caminho fazia-se a pé, em ranchos alegres e rumorosos, com adufes, pandeiros, harmoniuns, e gaitas de beiço, o que dava aso a descantes, cantigas ao desafio e às "modas" populares de que tão rico e belo é o nosso folclore» ${ }^{22}$.

Convém registar que as manifestações festivas se faziam mais no percurso de ida; no de regresso, já cansados, os romeiros pensavam mais em chegar a casa. $\mathrm{O}$ dichote popular que vem a seguir traduz este estado de espírito. «Para onde vais?» - Resposta alegre e exuberante: «vou para a festa!!!». «Donde vens?»-Resposta triste e sorumbática: «venho da festaiii».

A este propósito, é magistralmente ilustrativa a seguinte passagem de Aquilino Ribeiro: «O caminho para a romaria, salvo o que tinha de desintencional, era autêntica parada de folclore. Exumavam-se das arcas, dentre mentrastos, os trajes de ver a Deus: chailes de franjas, capotes com dois cabeções forrados de baeta vermelha e fivela de prata, chambrinhos vistosos, o chapéu braguês, chanquinhas de verniz, com uma prega de cores nos fêstos, que passam e vão largando o sonido quási musical do cascavel, lenços ramalhudos, gloriosos, produto duma estamparia ultra-impressionista concebida, dir-se-ia, para alegrar a alma dos melancólicos. Cantava-se a modinha, que teria inventado há que mundos o troveiro de ofício, aligeirando-se a jornada com as tocatas do harmónio ou o funfarrum da rabeca ou dos

${ }^{21}$ OLIVEIRA, Ernesto Veiga de - Festividades Cíclicas em Portugal. Lisboa: Publicações Dom Quixote, 1984, p. 219.

${ }^{22}$ CRESPO, José - Romarias Típicas da Beira. A Tia Baptista de Vinho. Beira Alta, Viseu: Assembleia Distrital de Viseu, 1984, vol. XLIII, nos 1 e 2, p. 281-289. 
ferrinhos. Os faias voltavam com o registo do orago entalado na fita do chapéu a par da pena de pavão e às vezes com a cabeça rachada $\rangle^{23}$.

${ }^{23}$ RIBEIRO, Aquilino - As Beiras sob o ponto de vista etnográfico, Seara Nova, no 731 (1941) 229. 